\title{
Reproducibility of a reaming test
}

Pilny, Lukas; Müller, Pavel; De Chiffre, Leonardo

Published in:

International Journal of Manufacturing Research

Link to article, DOI:

10.1504/IJMR.2014.062441

Publication date:

2014

Document Version

Publisher's PDF, also known as Version of record

Link back to DTU Orbit

Citation (APA):

Pilny, L., Müller, P., \& De Chiffre, L. (2014). Reproducibility of a reaming test. International Journal of Manufacturing Research, 9(2), 157-172. https://doi.org/10.1504/IJMR.2014.062441

\section{General rights}

Copyright and moral rights for the publications made accessible in the public portal are retained by the authors and/or other copyright owners and it is a condition of accessing publications that users recognise and abide by the legal requirements associated with these rights.

- Users may download and print one copy of any publication from the public portal for the purpose of private study or research.

- You may not further distribute the material or use it for any profit-making activity or commercial gain

- You may freely distribute the URL identifying the publication in the public portal

If you believe that this document breaches copyright please contact us providing details, and we will remove access to the work immediately and investigate your claim. 


\title{
Reproducibility of a reaming test
}

\author{
L. Pilný*
}

Department of Mechanical Engineering, Technical University of Denmark, Produktionstorvet, Building 427S, DK-2800 Kgs. Lyngby, Denmark

E-mail: lupi@mek.dtu.dk

*Corresponding author

\section{P. Müller}

LEGO System A/S,

Åstvej, 7190 Billund, Denmark

\section{De Chiffre}

Department of Mechanical Engineering, Technical University of Denmark, Produktionstorvet, Building 425,

DK-2800 Kgs. Lyngby, Denmark

\begin{abstract}
The reproducibility of a reaming test was analysed to document its applicability as a performance test for cutting fluids. Reaming tests were carried out on a drilling machine using HSS reamers. Workpiece material was an austenitic stainless steel, machined using $4.75 \mathrm{~m} \cdot \mathrm{min}^{-1}$ cutting speed and $0.3 \mathrm{~mm} \cdot \mathrm{rev}^{-1}$ feed. A mineral straight oil and a water-based lubricant at two different oil concentrations were compared with respect to hole quality, evaluated in terms of surface finish (conventional arithmetic mean roughness $\mathrm{Ra}$ and roughness profiles), and hole geometry (hole diameter and roundness). Process reproducibility was assessed as the ability of different operators to ensure a consistent rating of individual lubricants. Absolute average values as well as experimental standard deviations of the evaluation parameters were calculated, and uncertainty budgeting was performed. Results document a built-up edge occurrence hindering a robust evaluation of cutting fluid performance, if the data evaluation is based on surface finish only. Measurements of hole geometry provide documentation to recognise systematic error distorting the performance test.
\end{abstract}

[Received 14 May 2013; Revised 30 September 2013; Accepted 13 October 2013]

Keywords: cutting fluid test; reaming; process reproducibility; test uncertainty; surface finish; hole geometry; built-up edge; BUE.

Reference to this paper should be made as follows: Pilný, L., Müller, P. and De Chiffre, L. (2014) 'Reproducibility of a reaming test', Int. J. Manufacturing Research, Vol. 9, No. 2, pp.157-172. 
Biographical notes: L. Pilný graduated in Mechanical Engineering (process technology) - Machining, Metal Forming, Welding, and Metrology from the Brno University of Technology (BUT) in the Czech Republic. He is currently working as a PhD student at the Technical University of Denmark (DTU) in process monitoring and control of manufacturing processes. He holds school leaving certificate in $\mathrm{CNC}$ programming of machine tool, creation of technical drawings and solid modelling.

P. Müller received his PhD degree from the Technical University of Denmark, Mechanical Engineering, based on his work on coordinate metrology by traceable computed tomography. He received his MSc in Mechanical Engineering from the Brno University of Technology in the Czech Republic. His main areas of interest are: coordinate metrology, geometrical metrology, measurement uncertainty estimation and process technology - machining. From 2013, he has been employed at LEGO System A/S where he works as a Metrology Specialist with focus on projects and lean activities.

L. De Chiffre is a Full Professor at the Department of Mechanical Engineering, Technical University of Denmark (DTU) since 2002. He is an internationally recognised expert in manufacturing and metrology, having published over 200 technical papers in international journals and conference proceedings. His theoretical models quantifying the role of friction and lubrication in metal cutting are described in textbooks worldwide. He has been the Supervisor of more than $100 \mathrm{MSc}$ students and over $20 \mathrm{PhD}$ students. He has been initiator and coordinator of major framework programmes, and created and directed since its formation the Centre for Geometrical Metrology (CGM). Moreover, he has established a transnational virtual institute for geometrical metrology between DTU and Padova University. He is a Fellow of the International Academy for Production Engineering (CIRP) and panel member of the Foundation Committee of the European Society for Precision Engineering and Nanotechnologies (Euspen).

This paper is a revised and expanded version of a paper entitled 'Reproducibility of a reaming test' presented at Swedish Production Symposium SPS12, Linköping, Sweden, 6-8 November 2012.

\section{Introduction}

An application of cutting fluids in machining operations is well known to provide greater tool life, reduction of cutting forces, improved surface characteristics and geometrical accuracy, thus resulting in improved process efficiency. This is due to cooling and lubrication properties of the cutting fluid and their interaction (De Chiffre, 1988; Shaw, 2005). There is a large variety of cutting fluids on the market and various methods of their application. For example, Doshi et al. (2013) discusses on the substitution of conventional coolants by nanofluids (dispersing nanometre size structure in a base fluid in colloidal state) for enhanced performance during machining of difficult-to-cut materials. Zedan et al. (2013) investigates the effects of the cutting fluid and application mode (dry, mist and flood drilling) and its interaction with cutting parameters on part quality.

According to De Chiffre and Belluco (2000), there is no single test method of cutting fluid efficiency embracing all machining operations. Selection of an appropriate cutting 
fluid has to be based on testing under practical operating conditions but keeping all influence parameters under close laboratory control. Axinte et al. (2003) experimentally documented the difficulty of identifying the best cutting fluid, especially when several different machining methods were employed. Prioritisation of the output measures and specification of the relative importance of each machining operation was suggested. Haan et al. (1997) carried out an extensive research on the effects of cutting fluids in drilling operations. Results indicated no significant effect between two water-soluble oils ( 2 and $8 \%$ concentrations respectively). On the contrary, significantly larger average surface finish and its variation when cutting dry compared to the use of cutting fluid were observed. Xavior and Adithan (2010) investigated the influence of different cutting fluids on tool-shim interface temperature and the cutting force developed during turning of AISI 304 stainless steel. The study reports vegetable-based oil outperforming other cutting fluids investigated in terms of chosen evaluation criteria.

De Chiffre et al. (1994) proposed a reaming test as a method for the assessment of cutting fluid lubrication efficiency, based on researches related to the development of performance tests for cutting fluids at the Technical University of Denmark (DTU) (De Chiffre, 1977; De Chiffre et al., 1994). From an operation point of view, requirement on lubricating efficiency of cutting fluid is pronounced for reaming operation due to low speeds and feed rates generally utilised, allowing built-up edge (BUE) occurrence. From a test point of view, reaming test provides easier surface quality evaluation compared to e.g., tapping, previously proposed as standardised test procedure by Lorenz (1985).

This study is related to the continuous research at DTU concerning the development of performance tests for cutting fluids (De Chiffre and Belluco, 2000; Belluco, 2000; De Chiffre et al., 2001, 2009; Müller and De Chiffre, 2011; Müller et al., 2012), in particular those involving measurements of product quality (De Chiffre et al., 1994; De Chiffre, 1988; Müller and De Chiffre, 2011). This paper aims to document and provide more robust test procedure for comparison of lubricants.

\section{Experimental conditions}

All the reaming tests were carried out on a $3.7 \mathrm{~kW}$ Modig vertical drilling machine. Three high speed steel 6-flute left hand helix $\left(-7^{\circ}\right)$ machine reamers $ø 10.8$ H7 DIN 212 form D, HSS-E were used for the tests. The reamers were clamped in a floating holder SK30 $\times$ MK3 Gewefa, which enables to accurately align with the pre-manufactured hole (i.e., pilot hole).

Specimens were austenitic steel AISI 316L. Belluco (2000), De Chiffre et al. (2009), and Müller et al. (2012) performed investigations using the same specimens (material and dimensions) to investigate the efficiency of cutting fluids in multiple machining operations and to document a process capability using metrological approach, respectively. The workpiece material characteristics are summarised in Table 1. As discussed by Kaladhar et al. (2012), such material is difficult to machine owing to its ductility, low thermal conductivity and high strain hardening. Such properties cause ease of work hardening if machining parameters are not chosen correctly.

The test workpieces were rings of diameter 29 and height of $30 \mathrm{~mm}$ with pre-manufactured holes of $10.3 \mathrm{~mm}$ in diameter by reaming. Belluco (2000) has previously specified the dimensional characteristics and surface roughness of the 
workpieces. Workpieces were clamped in a dedicated holder so that the workpieces were fully immersed in the cutting fluid.

Table 1 Workpiece material characteristics

\begin{tabular}{|c|c|c|c|}
\hline $\begin{array}{l}\text { Workpiece material } \\
\text { Vickers hardness }\end{array}$ & & \multicolumn{2}{|c|}{ AISI 316 L stainless steel } \\
\hline \multicolumn{4}{|c|}{ Composition analysis } \\
\hline Element & Mass in \% & Element & Mass in \% \\
\hline $\mathrm{C}$ & 0.016 & $\mathrm{Cr}$ & 17.31 \\
\hline $\mathrm{Si}$ & 0.39 & Mo & 2.11 \\
\hline $\mathrm{Mn}$ & 1.4 & $\mathrm{~S}$ & 0.026 \\
\hline $\mathrm{P}$ & 0.027 & $\mathrm{~N}$ & 0.052 \\
\hline $\mathrm{Ni}$ & 11.21 & & \\
\hline
\end{tabular}

Source: De Chiffre et al. (2009)

Three cutting fluids selected in accordance with Müller and De Chiffre (2011) was used throughout the test (see Table 2). The workpieces were fully immersed in the cutting fluid during the cutting. The order of the application of each lubricant is discussed in Section 5 - experimental plan.

Table 2 Summary of tested cutting fluids

\begin{tabular}{llc}
\hline Code & Description & Oil concentration in \% \\
\hline WB1 & Amine-free water-based cooling lubricant & 1 \\
WB10 & Amine-free water-based cooling lubricant & 10 \\
MO & Mineral straight oil & 100 \\
\hline
\end{tabular}

Cutting conditions based on previous experience in reaming austenitic stainless steel with HSS reamers were selected. In particular, cutting speed of $4.75 \mathrm{~m} \cdot \mathrm{min}^{-1}$ and feed per revolution of $0.3 \mathrm{~mm}$ were employed.

\section{Measurement procedures}

\subsection{Surface roughness measurement}

Surface topography of the reamed holes was characterised in terms of conventional surface roughness parameters $\mathrm{Ra}$, defined by International Organization for Standardization (1997). Measurements were carried out using a stylus roughness tester, Surtronic 4+, equipped with a skid pick-up and a $2 \mu \mathrm{m}$ radius tip according to International Organization for Standardization (1998). The instrument was calibrated before the actual measurement series using an optical flat, to determine the background noise and an ISO 5436 type $\mathrm{C}$ roughness standard, to determine the repeatability of the measurement.

Surface profiles were recorded at three different positions on the reamed specimens, approx. equally distributed around the hole circumference, at a distance approx. $5 \mathrm{~mm}$ from the top surface (see Figure 1). The specimens were sub sequentially turned and 
measured, following the same strategy, at the bottom at a distance approx. $5 \mathrm{~mm}$ from the bottom face of the workpiece. An evaluation length $\ln =4 \mathrm{~mm}$, low-pass $\lambda \mathrm{s}=0 \mu \mathrm{m}$ and high-pass $\lambda c=0.8 \mathrm{~mm}$ profile filtering, according to International Organization for Standardization (1998), were applied.

Figure 1 Indication of the measured positions for surface roughness measurements

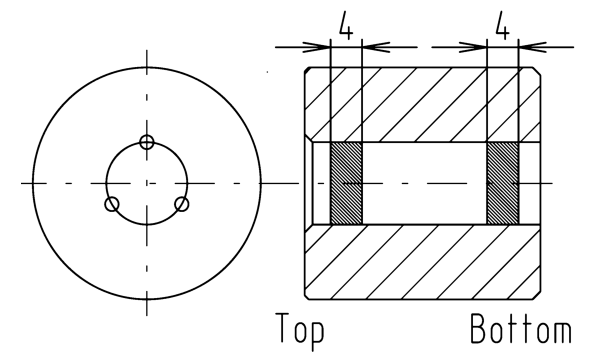

\subsection{Hole geometry measurement}

Geometrical characteristics of the workpieces - diameter and roundness - were measured using a tactile coordinate measuring machine (TCMM).

The reamed holes were measured at five levels determined along the workpiece height (see Figure 2). Twelve points equally distributed around the hole circumference were taken at each level of the hole. Measuring strategy with five levels and 12 points was applied to better understand the effect of the cutting fluids on selected parameters, which could not be achieved if less levels or number of points were chosen. The selection of the measuring strategy (12 points, five levels) was based on preliminary measurements carried out on a master piece. Since the machine was checked for accuracy prior measurement by measuring a reference ring (standard uncertainty was estimated to be $0.1 \mu \mathrm{m}$ ) and uncertainty due to measuring repeatability was assessed on a master piece (standard uncertainty was estimated to be $1.6 \mu \mathrm{m}$ ), workpieces were measured only once.

Figure 2 Indication of the measured vertical positions for hole diameter and roundness measurements

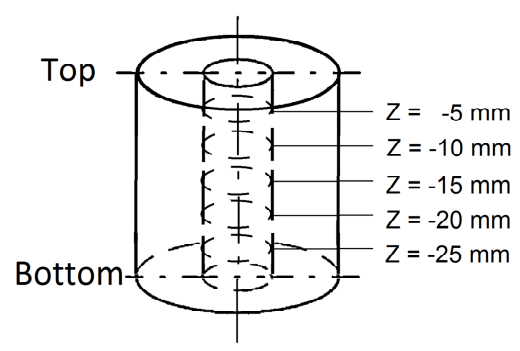

\section{Uncertainty assessment for surface roughness measurements}

Uncertainty of surface roughness measurements were calculated according to the International Organization for Standardization (2008), GUM method, as follows: 


$$
U_{R O U G H}(R a)=k \cdot \sqrt{u_{I N S}^{2}+u_{s}^{2}}
$$

where

- $\quad U_{\text {ROUGH }}(R a)=$ expanded uncertainty of surface roughness measurements on reamed holes for Ra surface roughness parameter

- $k=$ coverage factor $(k=2$ for a confidence level of $95 \%)$

- $u_{\mathrm{INS}}=$ standard uncertainty of the instrument, taking into account uncertainty from calibration of the instrument using a roughness standard, repeatability of the instrument and uncertainty caused due to the background noise

- $u_{\mathrm{S}}=$ standard uncertainty caused by variations in the roughness of the specimen in different locations, considering different workpieces from the same batch and different operators; $u_{\mathrm{S}}=S T D_{\mathrm{S}} / v_{n}$, where $n$ is the number of measurements carried out on all the specimens for one cutting fluid with standard deviation $S T D_{\mathrm{S}}$.

Estimated expanded measurement uncertainty due to the instrument calibration was $0.014 \mu \mathrm{m}$.

\section{Uncertainty assessment for hole geometry measurements}

Measurement uncertainty for measurements using TCMM was assessed following the International Organization for Standardization (2011), PUMA method. This ISO standard is based on assessing the influence of individual uncertainty contributors on the measurand and creation of a simplified uncertainty budget. In our case, six uncertainty contributors were taken into consideration. The uncertainty of the reamed holes $U_{\mathrm{GEOM}}$ was then calculated as follows:

$$
U_{\mathrm{GEOM}}(j)=k \cdot \sqrt{u_{\mathrm{CAL}}^{2}+u_{\mathrm{REPEAT}}^{2}+u_{\mathrm{PILOT}}^{2}+u_{\mathrm{STRATEGY}}^{2}+u_{\mathrm{WP}}^{2}+u_{\mathrm{ENV}}^{2}}
$$

where

- $\quad U_{\mathrm{GEOM}}(j)=$ expanded uncertainty of geometrical measurements of reamed holes, $j=(\mathrm{D}, \mathrm{R})$ is the measurand: diameter and roundness.

- $k=$ coverage factor $(=2)$ for a confidence level of $95 \%$.

- $u_{\mathrm{CAL}}=$ standard calibration uncertainty of the reference ring, calculated as $u_{\mathrm{CAL}}=U_{\text {cert,GEOM }} / 2$, where $U_{\text {cert,GEOM }}$ is the expanded uncertainty of the reference ring stated in the certificate.

- $\quad u_{\text {REPEAT }}=$ standard uncertainty of machine repeatability, evaluated using a reference ring, taking into account the influence of measuring strategy investigated on a reference ring.

- $\quad u_{\text {PILOT }}=$ standard uncertainty of the pilot hole, evaluated on ten randomly selected workpieces from the batch, taking into account repeated measurements carried out on each workpiece. 
- $\quad u_{\text {STRATEGY }}=$ standard uncertainty of the measuring strategy using CMM, determined on a master piece - a workpiece randomly selected from the production batch. The influence of number of measured points at each level, and number of levels on a workpiece was taken into account.

- $\quad u_{\mathrm{WP}}=$ standard uncertainty of the reamed workpieces, calculated as a maximum standard deviation considering reproducibility of the reaming process in three days and variation of workpieces in the batch.

- $u_{\mathrm{ENV}}=$ temperature-related standard uncertainty, calculated for a maximum temperature variation of $\pm 1{ }^{\circ} \mathrm{C}$, taking into account the thermal expansion coefficient of the workpiece.

All measurement results were first corrected for measurement bias, which was determined through measurements on a calibrated reference ring and comparison to the reference value from a certificate of the reference ring. Evaluated measured bias was $0.007 \mathrm{~mm}$.

\section{Experimental plan}

Cutting conditions specified in Section 2 were applied by three operators, performing the test in different days. The influence of the operator on defined evaluation parameters (measurands) in terms of surface roughness and reamed hole geometry (diameter and roundness) was investigated. Each operator randomly chosen 18 specimens from a production batch, and assigned each six specimens to be reamed using different cutting fluids. Each operator used the three cutting fluids in the same following order: WB1-WB10-M.O. The tool and the reservoir were cleaned during each cutting fluid change. A new reamer was used by each operator performing the test in different days. The reamers were measured before the tests to control the actual diameter of the hole and reaming of five workpieces was used as run-in preceding the actual test.

\section{Results and discussion}

Different lubrication efficiency of the cutting fluids could already be seen during the cutting, where different types of chips were observed. Cutting with water-based cutting fluids (WB1 and WB10) provided lamellar chips having very short length for WB1 and slightly longer for WB10. While the process using pure mineral oil (MO) provided long flow chips. Different chip formation mechanisms were caused by different lubricating conditions where better lubricant causes greater restriction of contact area between the tool rake face and workpiece being cut off in form of chip. Smaller contact area results in smaller friction, less inclination to the occurrence of BUE, smaller cutting forces required and smaller degree of deformation of the chip (e.g., flow type chips). 


\subsection{Surface roughness measurement}

\subsubsection{Ra parameter}

Results of the surface roughness $\mathrm{Ra}$ (see Figure 3 left) indicate that generally this parameter is slightly smaller for measurements at the top of the hole and bigger at the bottom of the hole. However, the difference is small. Comparing different cutting fluids, one can observe smaller Ra values by approx. $0.1 \mu \mathrm{m}$ when cutting using WB10. However, the difference is not substantial compared to the other cutting fluids. Taking into account stochastic nature of surface roughness (De Chiffre and Belluco, 2000), such a variation will not provide robust information if one lubricant is better than the other is. All the three operators performed the cutting with a moderate reproducibility (considering the average values only). The results of measurement uncertainties, calculated at a confidence level of $95 \%(k=2)$, are shown in Figure 3 right. Measurement uncertainties obtained for measurements at the top of the bores are of approx. the same magnitude for all tested cutting fluids (approx. $0.020 \mu \mathrm{m}$ ) with small variability. On the contrary, uncertainties for measurements at the bottom are of bigger magnitude with great variability, directly indicating instability of the process. The uncertainties calculated for measurements at the top and the bottom of the hole are in the similar range for all three cutting fluids.

Figure 3 Results of the mean surface roughness parameter Ra, (a) measured by three operators at the top and at the bottom of reamed holes for each tested cutting fluid (b) associated expanded measurement uncertainties (right)

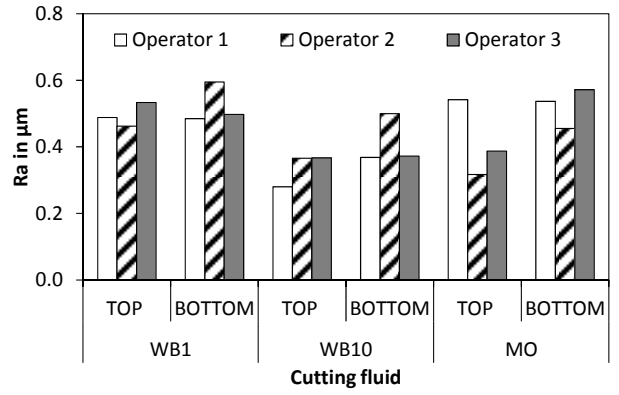

(a)

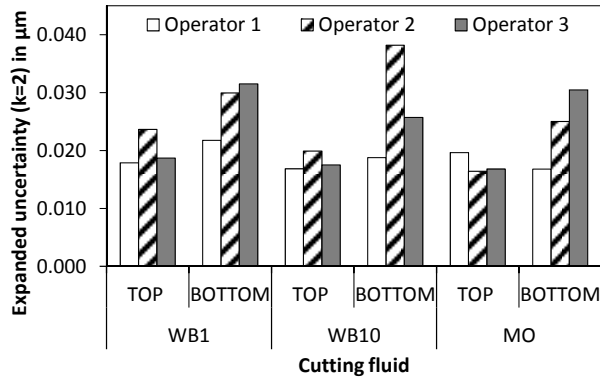

(b)

Table 3 presents results of repeatability of the tests. Test repeatability is represented by experimental standard deviation of measurements with a given cutting fluid, expressed in percentage of the average test result. De Chiffre and Belluco (2000) discuss that reaming tests, particularly tests involving cutting of the stainless steel, yield repeatability in the range 5 to $60 \%$ when using water-based and 5 to $30 \%$ when using oil as a lubricant. In this study, test repeatability also fell in this range.

\subsubsection{Surface roughness profiles}

Surface roughness profiles measured in the reamed holes are generally reproducible for all three cutting fluids, considering nine randomly selected workpieces from the batch, as well as different operators. 
Table 3 Test repeatability considering surface roughness Ra, expressed in \%

\begin{tabular}{lcccccccc}
\hline \multirow{2}{*}{ Oper. no. } & \multicolumn{2}{c}{ WB1 } & & \multicolumn{2}{c}{ WB10 } & & \multicolumn{3}{c}{ MO } \\
\cline { 2 - 3 } \cline { 7 - 9 } \cline { 7 - 9 } & Top & Bottom & & Top & Bottom & & Top & Bottom \\
\hline 1 & 20 & 31 & & 30 & 30 & & 16 & 23 \\
2 & 25 & 33 & & 31 & 43 & & 19 & 20 \\
3 & 15 & 26 & & 26 & 29 & & 18 & 24 \\
\hline
\end{tabular}

Higher reproducibility of the profiles was achieved for measurements at the top of the holes. At this point it is difficult to recognise the reasons for these differences, but it is discussed in the following section. Figure 4 presents an example of the profiles taken at the top and at the bottom of three different reamed holes for each of all the three cutting fluids. First, one can observe that a clear difference between the appearance of the profiles at the top and at the bottom exists. Taking into account the parameter Ra (arithmetic mean), the values of this parameter for each of the fluid at both the top and the bottom are similar, which in many cases may lead to wrong interpretations of the results. However, good reproducibility (similar appearance) of the profiles can be recognised for measurements at the top and at the bottom of the hole.

Figure 4 Nature and reproducibility of surface roughness profiles of reamed holes with different cutting fluids, (a) WB1 (b) WB10 (c) MO (see online version for colours)

TOP
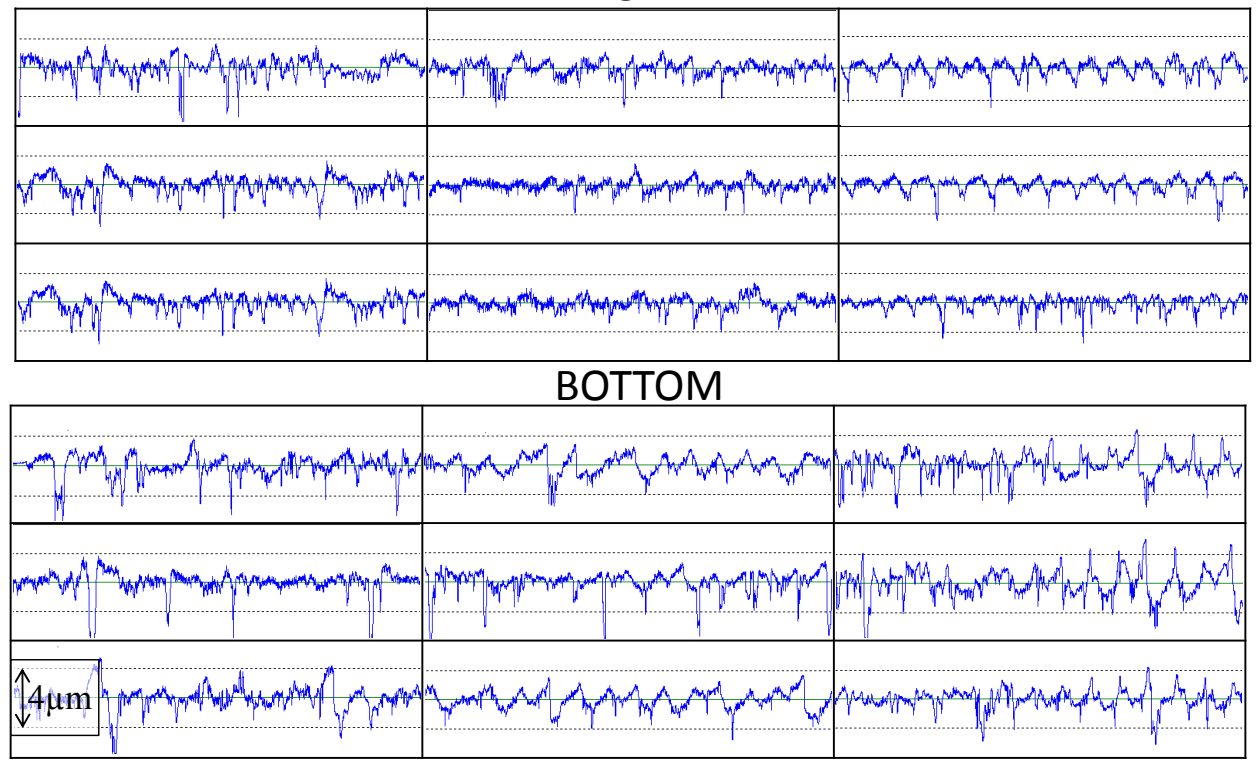

(a)

(b)

(c)

Note: Length of all the profiles is $4 \mathrm{~mm}$, vertical scale is shown in the left bottom figure.

Müller and De Chiffre (2011) shown that mean surface roughness parameter Ra may exhibits loss of information, and it is always recommended to take the original profiles into account. 
At this stage of the investigation, it is not possible to provide consistent rating of the cutting fluids because the results of the mean surface roughness parameter Ra are of approx. the same magnitude, even though having different surface roughness profile appearance. Therefore, further investigation on the quality of the reamed holes in terms of measurements of hole diameter and hole roundness were carried out. As described in earlier work by De Chiffre et al. (1994) and Belluco (2000), the two measurands belong to the typical performance criteria in reaming.

\subsection{Hole geometry measurements}

\subsubsection{Diameter}

Figure 5 shows diameter of reamed holes, for 1 operator, measured at five different levels along specimens height, clearly showing its increase in the direction of feed of the tool, i.e., measurands smaller diameter at the top of the hole where the reamer starts to cut the workpiece and bigger towards the bottom. This behaviour is hardly distinguishable when using cutting fluid WB1 whereas more pronounced for the other cutting fluids WB10 and MO. This is attributed to be likely due to BUE occurrence during the process as discussed in the following. Uncertainty calculation is based on contributor $u_{\mathrm{WP}}$ considering variability of workpieces in the batch only, due to only one operator performing the test.

Figure 5 Reamed hole diameter measured at five different levels along specimen height for the three tested cutting fluids, operator 1 (see online version for colours)

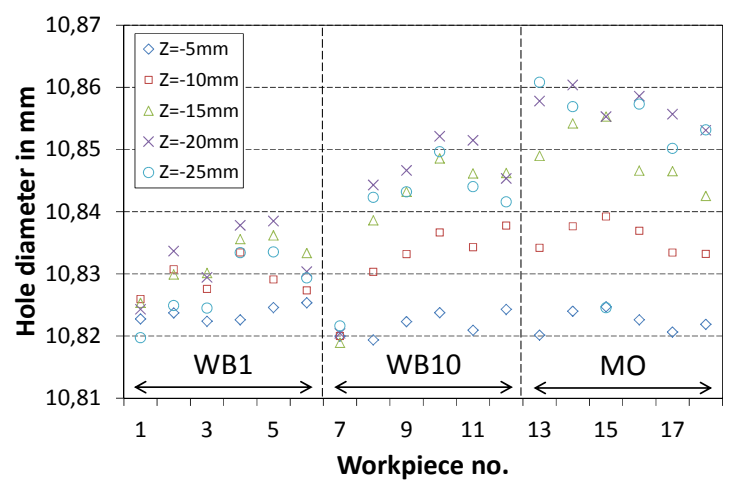

Note: Expanded measurement uncertainty $(k=2) U=0.008 \mathrm{~mm}$.

Reproducibility of reamed hole diameter by three different operators is shown in Figure 6, taking into account the two most distinct measured levels of the workpieces (top and bottom). The graph shows high reproducibility within approx. $10 \mu \mathrm{m}$ of the hole diameter measured at the top level whereas poor reproducibility of approx. $50 \mu \mathrm{m}$ measured at the bottom level. This confirms the assertion of BUE occurrence since a substantial amount of BUE would naturally be removed by the first contact between the tool and workpiece, reflected by more regular and repeatable geometry of reamed bore represented by the top measured level in Figures 5 and 6 . The greater scatter of reamed diameter measured at the bottom level of the specimen reflects a stochastic nature of BUE (accumulation and break off) and thus poor reproducibility. 
Figure 6 Reproducibility of the reamed hole diameter measured at two different levels along specimen height (top $Z=-5 \mathrm{~mm}$ and bottom $Z=-25 \mathrm{~mm}$ ) for the three tested cutting fluids (see online version for colours)

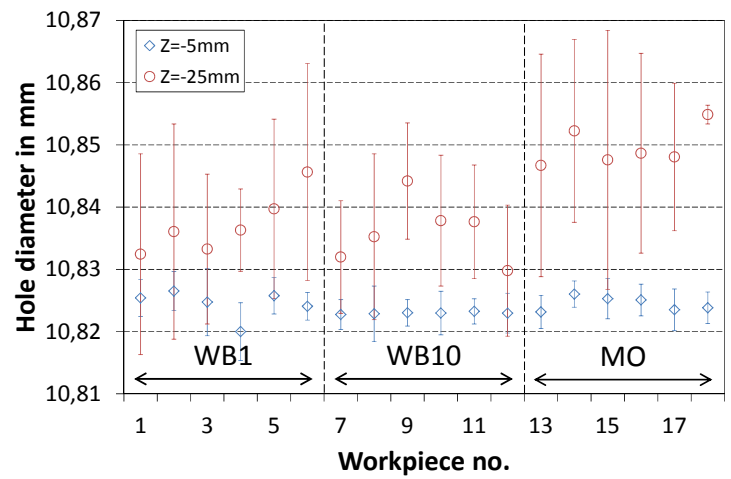

Note: Error bars representing expanded measurement uncertainty $U$ considering three operators.

\subsubsection{Roundness}

Roundness of reamed holes measured at five different levels along workpieces height for the three tested cutting fluids by single operator is depicted in Figure 7. The measured data shows two times greater scatter of reamed holes roundness along the tool feed direction when using WB1 cutting fluid compared to WB10 and MO. This behaviour is assumed to be due to faster reoccurrence of BUE (creation and break off) when cutting fluid having worse lubrication utilised, resulting in cutting with changing cutting edge geometry and thus poor bore roundness. The better lubrication, the slower accumulation of BUE, providing more stable cutting edge geometry and thus better roundness (2D bore geometry).

Figure 7 Roundness of reamed holes measured at five different levels along specimen height for the three tested cutting fluids, operator 1 (see online version for colours)

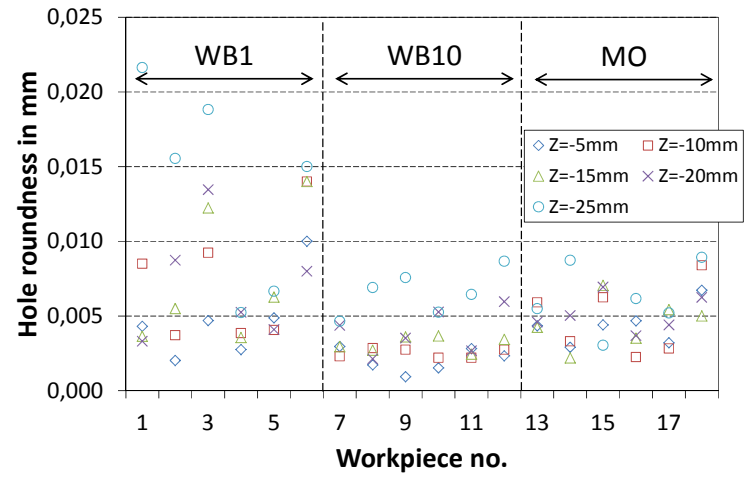

Note: Expanded measurement uncertainty $(k=2) U=0.008 \mathrm{~mm}$. 
Roundness reproducibility of reamed holes based on three different operators is depicted at the top and bottom measured levels in Figure 8. The top level exhibits smaller variability over number of reamed holes utilising different cutting fluids, mostly reflecting variation in the remaining amount of BUE after its break off due to the first contact of the tool with the workpiece. The bottom level shows bigger roundness error owing to faster reoccurrence of BUE and great variability when using cutting fluid WB1, directly reflecting stochastic nature of BUE. Cutting fluids having better lubrication properties, WB10 and MO respectively, exhibit decrease in roundness and its variability. This is due to more constant cutting edge geometry during slower BUE accumulation.

Figure 8 Reproducibility of the reamed hole roundness measured at two different levels along specimen height (top $Z=-5 \mathrm{~mm}$ and bottom $Z=-25 \mathrm{~mm}$ ) for the three tested cutting fluids (see online version for colours)

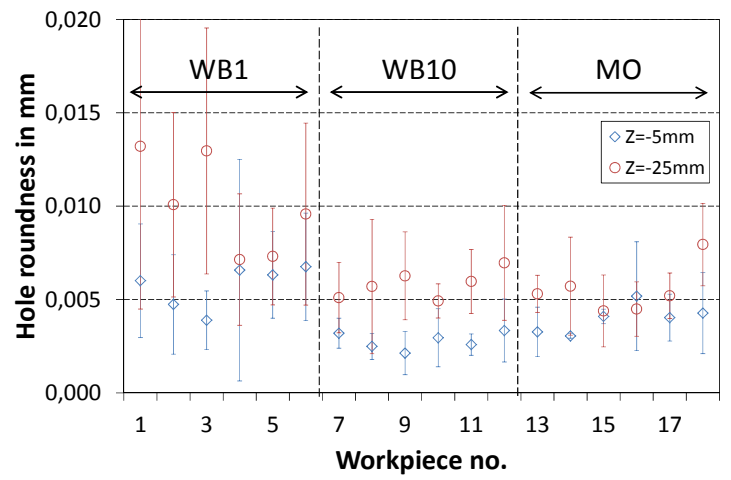

Note: Error bars representing expanded measurement uncertainty $U$ considering three operators.

It can be observed from Figures 5 to 8 that there is an opposing cross correlation of reamed holes diameter (increasing trend) and holes roundness (decreasing trend) for the three tested cutting fluids and three operators. This is directly showing the effect of BUE formation on reamed hole geometry, while the effect on the test reproducibility was previously discussed. Huerta et al. (2010) showed that surface quality is strongly influenced by the tool surface changes in form of BUE and built-up layer (BUL). Evolution of both effects provokes an Ra reduction with the length of machining. Such behaviour is also seen in present investigation. To confirm our hypothesis about the occurrence of BUE, the used reaming tools were checked under the microscope and two reamed samples were cut in half and investigated by SEM for traces of BULs. Figure 9 shows found presence of BUE on the cutting edge of one of the used reaming tools and in Figure 10, two SEM photographs of BUL adhered on reamed surfaces are shown. These findings provide tangible evidence of BUE presence during the tests and BUL affecting the evaluation of cutting fluid performance. 
Table 4 Overall uncertainty budget for hole geometry measurements

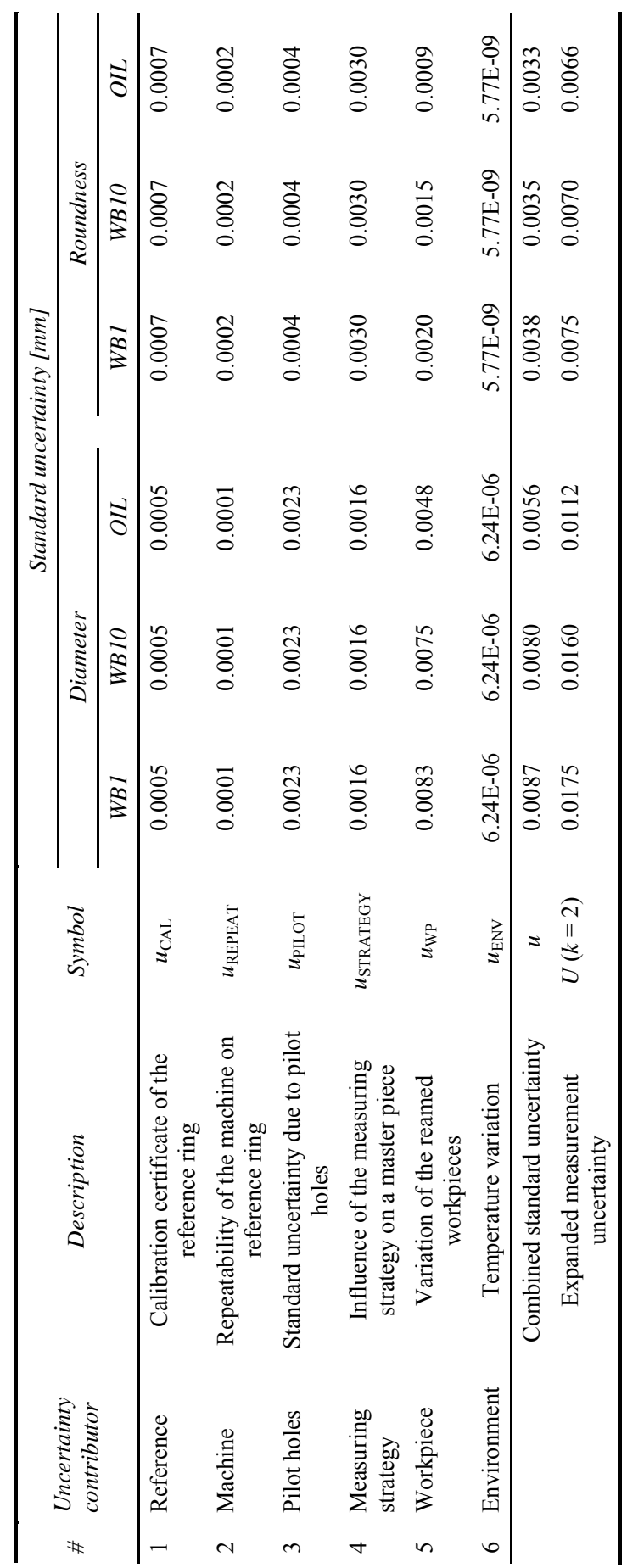


Figure 9 Occurrence of BUE on the tool's cutting edge (see online version for colours)

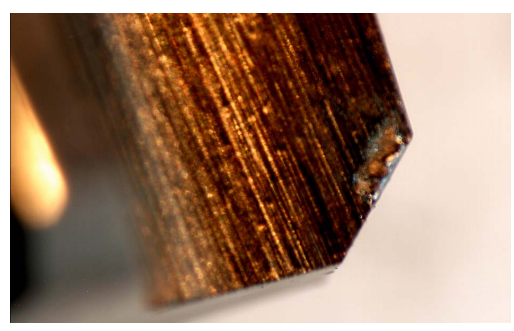

Figure 10 SEM images of built-up layers (BUL) on reamed surfaces
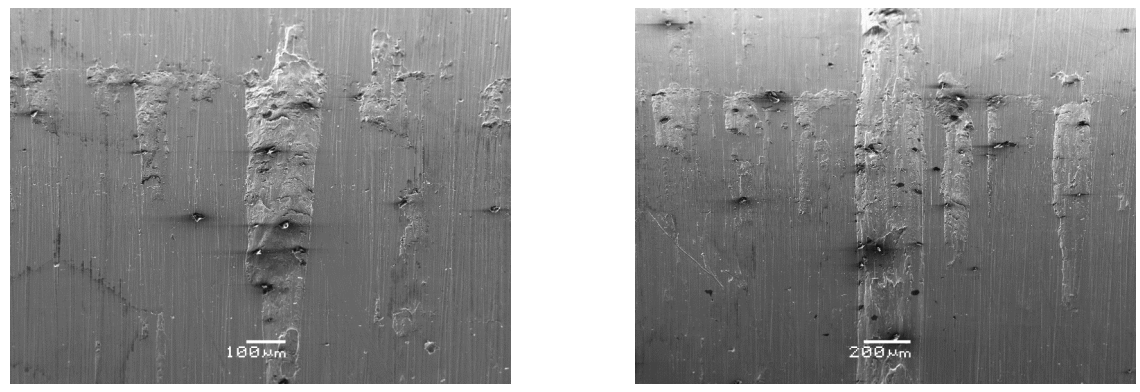

\section{Conclusions and outlook}

An investigation on a reaming test was carried out to document test reproducibility using a metrological approach. Tests were performed on a drilling machine using HSS reamers. Workpiece material was an austenitic stainless steel, machined by different operators using fixed cutting conditions. Three different lubricants were compared, using surface roughness and hole geometry as performance criteria. The process reproducibility was assessed as the ability of different operators to ensure a consistent rating of individual lubricants. Based on the results, the following conclusions are drawn:

- $\quad$ Reaming test is well reproducible by different operators, although consistent rating of individual lubricants can be hindered by systematic error (i.e., BUE).

- The reaming process is affected by BUE formation reoccurring on the cutting edge with periodical creation and break off, leaving residual BULs adhered on machined surface.

- This is reflected in tapered shape, deteriorated roundness, as well as different roughness at top and bottom in the reamed holes.

- Uncertainty of surface finish measurements at the top and the bottom of reamed holes indicates instability of the process.

- BUE can remain on the tool after the test and affect following tests. 
- Water-based cutting fluid WB1 resulted in small variation in bore diameter over the bore height while having bigger roundness error. This is due to poor lubrication of the cutting fluid, resulting in quickly changing effective cutting edge geometry owing to BUE formation.

- $\quad$ On the contrary, the use of cutting fluids with better lubrication properties, WB10 and MO respectively, resulted in tapered bore with better roundness achieved. This behaviour is caused by slowly increasing effective cutting edge geometry during the process due to BUE formation.

- The test has shown that if cutting fluid performance test is only based on quantitative comparison of the Ra roughness parameter, hidden influences as BUE may lead to wrong conclusions. Therefore, an additional analysis as, e.g., qualitative evaluation of roughness profiles, dimensional measurements, etc., is necessary.

Measurement of cutting forces (cutting thrust and torque) is expected to add relevant information of the test. Changing the order of lubricants tested or replacing the cutting tool by a new one for each tested cutting fluid should also be considered to provide more robust evaluation. Further study should be dedicated to the choice of better, or combination of more, surface roughness parameters to strengthen robustness of quantitative judging of cutting fluid performance based on surface roughness measurements.

\section{References}

Axinte, D., Axinte, M. and Tannock, J.D.T. (2003) 'A multicriteria model for cutting fluid evaluation', Proceedings of the Institution of Mechanical Engineers, Part B: Journal of Engineering Manufacture, Vol. 217, No. 10, pp.1341-1353, doi: 10.1243/095440503322617117.

Belluco, W. (2000) Performance Testing of Cutting Fluids, PhD thesis, Technical University of Denmark.

De Chiffre, L. (1977) 'Mechanics of metal cutting and cutting fluid action', International Journal of Machine Tool Design and Research, Vol. 17, No. 4, pp.225-234.

De Chiffre, L. (1988) 'Function of cutting fluids in machining', Lubrication Engineering, Vol. 44, No. 6, pp.514-518.

De Chiffre, L. and Belluco, W. (2000) 'Comparison of methods for cutting fluid performance testing', Annals of CIRP, Vol. 49, No. 1, pp.57-60.

De Chiffre, L., Lassen, S., Pedersen, K.B. and Skade, S. (1994) 'A reaming test for cutting fluid evaluation', Journal of Synthetic Lubrication, Vol. 11, No. 11, pp.17-34.

De Chiffre, L., Tosello, G., Piska, M. and Müller, P. (2009) 'Investigation on capability of reaming process using minimal quantity lubrication', CIRP Journal of Manufacturing Science and Technology, Vol. 2, No. 1, pp.47-54.

De Chiffre, L., Zeng, Z. and Belluco, W. (2001) 'An investigation of reaming test parameters used for cutting fluid evaluations', Lubrication Engineering, Vol. 57, No. 7, pp.24-28.

Doshi, S.J., Jain, P.K. and Mehta, N.K. (2013) 'Prospective applications of nano fluid during machining process', Int. J. Machining and Machinability of Materials, Vol. 14, No. 3, pp. 257-274.

Haan, D.M., Batzer, S.A., Olson, W.W. and Sutherland, J. (1997) 'An experimental study of cutting fluid effects in drilling', Journal of Material Processing Technology, Vol. 71, No. 2, pp.305-313. 
Huerta, M., Sánchez Carrilero, M., Álvarez, M., Salguero, J., Marcos, M. and Arroyo, P. (2010) 'Surface finish based analysis of turned titanium alloys workpieces', Int. J. Mechatronics and Manufacturing Systems, Vol. 3, No. 5, pp.380-392.

International Organization for Standardization (1997) ISO 4287:1997: Geometrical Product Specifications (GPS) - Surface Texture: Profile Method - Terms, Definitions and Surface Texture Parameters, ISO, Geneva.

International Organization for Standardization (1998) ISO 3274:1998: Geometrical Product Specifications (GPS) - Surface Texture: Profile Method - Nominal Characteristics of Contact (Stylus) Instruments, ISO, Geneva.

International Organization for Standardization (2008) ISO/IEC Guide 98-3:2008 - Uncertainty of Measurement - Part 3: Guide to the Expression of Uncertainty in Measurement (GUM:1995), ISO, Geneva.

International Organization for Standardization (2011) ISO 14253-2:2011 - Geometrical Product Specifications (GPS) - Inspection by Measurement of Workpieces and Measuring Equipment - Part 2: Guidance for the Estimation of Uncertainty in GPS Measurement, in Calibration of Measuring Equipment and in Product Verification.

Kaladhar, M., Subbaiah, K.V. and Rao, C.H.S. (2012) 'Machining of austenitic stainless steels - a review', Int. J. Machining and Machinability of Materials, Vol. 12, No. 1, pp.178-192.

Lorenz, G. (1985) 'Reliable cutting fluid rating', Annals of CIRP, Vol. 34, No. 1, pp.95-99.

Müller, P. and De Chiffre, L. (2011) 'Reproducibility of surface roughness in reaming', Proceedings of the 4th International Swedish Production Symposium (SPS11), pp.518-524.

Müller, P., Genta, G., Barbato, G., De Chiffre, L. and Levi, R. (2012) 'Reaming process improvement and control: an application of statistical engineering', CIRP Journal of Manufacturing Science and Technology, Vol. 5, No. 3, pp.196-201.

Shaw, M.C. (2005) Metal Cutting Principles, 2nd ed., Oxford University Press, New York, USA.

Xavior, M.A. and Adithan, M. (2010) 'Evaluating the performance of cutting fluids in machining of AISI 304 austenitic stainless steel', Int. J. Machining and Machinability of Materials, Vol. 7, No. 3, pp.244-259.

Zedan, Y., Songmene, V., Kouam, J. and Masounave, J. (2013) 'Effects of lubrication modes on part quality during drilling 6061-T6 aluminium alloy', Int. J. Machining and Machinability of Materials, Vol. 13, No. 2, pp.231-252. 